\title{
Dynamics of proopiomelanocortin and prohormone convertase 2 gene expression in Xenopus melanotrope cells during long-term background adaptation
}

\author{
C H Dotman, F van Herp ${ }^{1}$, G J M Martens ${ }^{1}$, B G Jenks and \\ E W Roubos
}

Department of Cellular Animal Physiology and ${ }^{1}$ Department of Molecular Animal Physiology, Nijmegen Institute for Neurosciences and Institute for Cellular Signalling, University of Nijmegen, Toernooiveld 1, 6525 ED Nijmegen, The Netherlands

(Requests for offprints should be addressed to B G Jenks)

\begin{abstract}
The toad Xenopus laevis is able to adapt its skin color to background light intensity. In this neuroendocrine reflex, the proopiomelanocortin (POMC)-derived peptide $\alpha$-melanophore-stimulating hormone $(\alpha \mathrm{MSH})$ is a key regulatory factor. In animals adapting to a black background, release of $\alpha \mathrm{MSH}$ from the pituitary pars intermedia causes dispersal of melanin in skin melanophores. To investigate the long-term in vivo dynamics of $\alpha \mathrm{MSH}$ production during black background adaptation, the biosynthetic rate of POMC and the contents of POMC, $\alpha \mathrm{MSH}$ and the POMC processing enzyme precursor convertase 2 (PC2) have been studied in the pars intermedia using pulse-labeling, Western blot and radioimmunoassay. In control animals, adapted to a white background, the rate of POMC biosynthesis and the POMC content were low, while high $\alpha \mathrm{MSH}$ and PC2 contents were found. After 1 week of adaptation to a black background, the rate of POMC biosynthesis and the
\end{abstract}

POMC protein content had increased 19- and 3.7-fold respectively. These parameters attained a maximum level (28- and 5.8-fold higher than control) after 3 weeks and remained at these elevated levels for at least 12 weeks. After 1 week, the pars intermedia content of $\alpha \mathrm{MSH}$ was only $30 \%$ of the control level, but after 6 and 12 weeks, the aMSH level had increased to the control level. The PC2 content decreased to $52 \%$ of control after 1 week and stabilized after 3 weeks at a level slightly lower than the control value. The results show that during long-term background adaptation a steady-state situation is reached, with a balance between the biosynthesis, enzymatic processing and release of $\alpha \mathrm{MSH}$. The in vivo dynamics of the processing enzyme PC2 suggest a parallel storage and release of $\alpha \mathrm{MSH}$ and mature PC2 in the Xenopus pituitary pars intermedia.

Journal of Endocrinology (1998) 159, 281-286

\section{Introduction}

Most amphibian species possess the ability to adapt the melanin pigment distribution in their skin melanophores to the light intensity of the background. In white background-adapted animals, melanin is aggregated around the nucleus, resulting in a pale skin color, while black background-adapted animals have a dark skin color, caused by pigment dispersal (Bagnara \& Hadley 1973). This process is a neuroendocrine reflex, mediated by the peptide $\alpha$-melanophore-stimulating hormone ( $\alpha \mathrm{MSH})$ (Wilson \& Morgan 1979, Jenks et al. 1988, van Zoest et al. 1989), which is produced in melanotrope cells of the pituitary pars intermedia from the precursor protein proopiomelanocortin (POMC) (Martens et al. 1985).

Differences in the physiologic demand for the amount of $\alpha \mathrm{MSH}$ released into the circulation are accompanied by plastic changes in the activity of melanotrope cells.
Because melanotrope cell activity can be readily influenced in a physiological way by changing the light intensity, amphibian background adaptation is an ideal model to study various structural and biochemical aspects of long-term plasticity in a secretory cell. In the toad Xenopus laevis some of the plastic cellular changes occurring in response to background adaptation have been studied in detail (for reviews see Jenks et al. 1993, Roubos 1997). The ultrastructure of melanotrope cells in white background-adapted animals reflects low biosynthetic activity, with the abundance of secretory granules indicating storage of $\alpha \mathrm{MSH}$. Transfer of animals from a white to a black background leads to an increase in the volume of rough endoplasmic reticulum, the extent of Golgi apparatus and the number of mitochondria, indicative of a high rate of POMC and $\alpha \mathrm{MSH}$ biosynthesis. These changes are accompanied by a decrease in the number of secretory granules, suggesting enhanced $\alpha \mathrm{MSH}$ release 
(Weatherhead \& Whur 1972, de Rijk et al. 1990). Such plastic changes in melanotrope cell activity have been confirmed in biochemical in vitro studies (Thornton 1971, Whur \& Weatherhead 1971, Jenks et al. 1977, Loh \& Gainer 1977, van Zoest et al. 1989).

In mammalian melanotropes, the processing enzyme prohormone convertase 2 (PC2) is responsible for the biosynthesis of $\alpha \mathrm{MSH}$ from the precursor protein POMC (Smith \& Funder 1988, Benjannet et al. 1991, Thomas et al. 1991, Day et al. 1992, Marcinkiewicz et al. 1993). POMC and PC2 are also coexpressed in Xenopus melanotropes. Much higher levels of POMC mRNA and PC2 mRNA occur in the pars intermedia of animals adapted to a black background compared with white background-adapted animals (Martens et al. 1987, Braks et al. 1992, Holthuis et al. 1995). At the subcellular level, PC2 has been localized in aMSH-containing secretory granules in Xenopus melanotropes, suggesting that also in amphibians PC2 is involved in proteolytic cleavage of POMC (Berghs et al. 1997, Kurabuchi \& Tanaka 1997). Processing of Xenopus POMC yields the same spectra of peptide products as in mammals (Martens et al. 1982a,b, 1983, van Strien et al. 1995, 1996).

Obviously, efficient functioning of the melanotrope cell during background adaptation requires a well-coordinated interplay between biosynthesis of POMC, POMC processing by $\mathrm{PC} 2$, and storage and release of $\alpha \mathrm{MSH}$. Up to now this interplay has been studied only fragmentarily. POMC biosynthesis and $\alpha \mathrm{MSH}$ release have been examined in short adaptation studies only (maximally 36 weeks; Maruthainar et al. 1992, Jenks et al. 1993, van Strien et al. 1995, 1996), whereas the dynamics of PC2 during background adaptation are unknown. In the present study the dynamics of POMC biosynthesis and processing and $\alpha \mathrm{MSH}$ storage and release have been examined in a long-term in vivo approach to monitor the physiological steady-state situation. To this end, the rate of POMC biosynthesis and the amounts of POMC and $\alpha \mathrm{MSH}$ were determined in the pars intermedia of the Xenopus pituitary for up to 12 weeks after transfer of the animals from a white to a black background. Furthermore, the in vivo role of PC2 in POMC processing was investigated by determining the PC2 protein content during this period.

\section{Materials and Methods}

\section{Animals}

Xenopus laevis were bred and reared under laboratory conditions at $22{ }^{\circ} \mathrm{C}$. Before the experiments, male animals of the same age and weight were kept for 3 weeks on a white background (121 white plastic buckets, four animals per bucket) under constant illumination. Lighting was with overhead daylight tube lamps (Osram L58 W/11) generating 3000 Lux at the water surface. Following adaptation to white background animals were either immediately killed (controls), or placed on a black background (12 1 black plastic buckets) for 1, 3, 6 or 12 weeks, again under constant illumination. The transfer time schedule was designed in such a way that all animals could be killed on the same day. After decapitation, neurointermediate lobes were rapidly dissected and immediately subjected to pulse-labeling with radioactive amino acids or collected on dry ice and stored at $-70{ }^{\circ} \mathrm{C}$ until further processing for Western blot or radioimmunoassay.

\section{Radioactive amino acid incorporation (POMC biosynthesis)}

Neurointermediate lobes were individually rinsed in Ringer's solution containing $112 \mathrm{mM} \mathrm{NaCl}, 2 \mathrm{mM}$ $\mathrm{CaCl}_{2}, 2$ mM KCl, 15 mM Ultral-Hepes (Calbiochem, La Jolla CA, USA), $0.3 \mathrm{mg} / \mathrm{ml} \mathrm{BSA}$ and $2 \mathrm{mg} / \mathrm{ml}$ glucose $(\mathrm{pH} 7 \cdot 4)$, and pulse-labeled for $30 \mathrm{~min}$ in $10 \mu \mathrm{l}$ Ringer's solution containing $1 \mathrm{mCi} / \mathrm{ml}\left[{ }^{3} \mathrm{H}\right]$ lysine (Amersham, Little Chalfont, Bucks, UK). Then they were washed in Ringer's solution and lyzed by boiling for $5 \mathrm{~min}$ in $100 \mu \mathrm{l}$ sample buffer containing $62.5 \mathrm{mM}$ Tris ( $\mathrm{pH} 6.8$ ), $12.5 \%$ glycerol, $1 \cdot 25 \%$ SDS, $2 \cdot 5 \% \quad \beta$-mercapto-ethanol and 0. $0125 \%$ bromophenol blue, prior to subjecting $20 \mu$ lobe extracts to $12 \cdot 5 \%$ SDS-PAGE.

\section{SDS-PAGE}

SDS-PAGE was performed according to Laemmli (1970). Subsequently, the gels were fixed (40\% methanol, 10\% acetic acid), saturated with $100 \%$ dimethylsulfoxide (DMSO) and treated with 20\% 2,5-diphenyloxazol (PPO) in $100 \%$ DMSO for fluorography (Bonner \& Laskey 1974). For analysis of results of pulse-labeling experiments, the $38 \mathrm{kDa}$ POMC protein can readily be identified in the electrophoretic pattern of a lobe extract (Ayoubi et al. 1990). Quantification of the amount of POMC protein (in arbitrary units) was performed with an UltroScan XL laser densitometer (Pharmacia LKB, Uppsala, Sweden).

\section{Western blot analysis (POMC and PC2 contents)}

Neurointermediate lobes were lysed by boiling in sample buffer, diluted 1:20 for POMC detection or 1:4 for PC2 detection, and subjected to $12 \cdot 5 \%$ SDS-PAGE. For immunoblotting, the proteins were electrophoretically transferred to nitrocellulose membranes using a MiniProtean II Cell system (Biorad, Segrate, Italy). Blots were incubated for $1 \mathrm{~h}$ in blocking buffer $(5 \%$ BSA in trisbuffered saline (TBS) with $0 \cdot 2 \%$ Tween-20), washed in TBST (TBS with 0.2\% Tween-20) and incubated for $16 \mathrm{~h}$ at $4{ }^{\circ} \mathrm{C}$ in blocking buffer with antisera against POMC or PC2. For POMC detection 1:10 000 diluted polyclonal rabbit anti-Xenopus POMC was used (ST-62; see Berghs et al. 1997, for details showing the high specificity of the antiserum). For PC2 detection a 1:1000 diluted polyclonal 
rabbit antiserum was used, produced against recombinant human PC2. This antiserum exclusively recognized the precursor and mature form of PC2 (see Fig. 2). Following incubation with antisera the blots were washed in TBST, incubated for $1 \mathrm{~h}$ at $20^{\circ} \mathrm{C}$ with $1: 1000$ diluted goat anti-rabbit $\operatorname{IgG}$ conjugated to peroxidase (Nordic, Tilburg, The Netherlands) in blocking buffer, and finally washed in $0.3 \mathrm{M} \mathrm{MgCl}_{2}$. Antigen was detected by the enhanced chemiluminescence method (Amersham). Quantification of the amounts of POMC and PC2 protein was performed as described above.

\section{Radioimmunoassay (aMSH contents)}

Neurointermediate lobes were homogenized in $0.1 \mathrm{M}$ $\mathrm{HCl}$, vacuum dried, resuspended, and subjected to a radioimmunoassay for $\alpha \mathrm{MSH}$ as described previously, using a polyclonal rabbit antiserum raised in our laboratory, at a final dilution of 1:30 000. Antibody-bound and free aMSH were separated by polyethylene glycol/ovalbumin precipitation (for details, see van Zoest et al. 1989).

\section{Statistics}

Data were analyzed by one-way analysis of variance $(\alpha=5 \%)$ (Bliss 1967) followed by Duncan's multiple range test (Steel \& Torrie 1960), to compare groups at different time points with each other. (These differences have been indicated by characters in the respective figures.) The analysis was preceded by tests for the joint assessment of normality (Shapiro \& Wilk 1965) and for the homogeneity of variance (Bartlett's test; Bliss 1967).

\section{Results}

\section{POMC biosynthesis}

The biosynthetic activity was measured by $\left[{ }^{3} \mathrm{H}\right]$ lysine labeling of POMC protein. The newly synthesized POMC was not detectably processed to smaller products during the short pulse incubation time of $30 \mathrm{~min}$, and thus the rate of precursor biosynthesis could be accurately determined. In white background-adapted animals, a very low level of POMC biosynthesis was observed, which increased after 3 weeks of black background adaptation to a level 28 times higher than the control level (animals adapted to a white background; Fig. 1A). The biosynthetic activity appeared to increase slightly up to 12 weeks, but this increase was not statistically significant.

\section{POMC contents}

Determination of the pars intermedia contents of the POMC precursor, excluding detection of POMC processing products, was possible by Western blot analysis using an antibody directed against the first cleavage site of Xenopus POMC. In the 3-week white backgroundadapted control animals, POMC precursor protein was present in a low amount (Fig. $1 \mathrm{~B}, \mathrm{t}=0$ ). During the first 3 weeks of black background adaptation, the POMC protein content increased to a maximum level. At 3 weeks, the amount of POMC was $5 \cdot 8$ times higher than that in white background-adapted animals. Subsequently, the content did not change significantly for up to 12 weeks (Fig. 1B).

\section{aMSH contents}

The pars intermedia of animals adapted to a white background contained a high amount of $\alpha \mathrm{MSH}$, as determined by radioimmunoassay (Fig. $1 \mathrm{C} ; \mathrm{t}=0$ ). After 1 week of adaptation to a black background, the tissue content of $\alpha \mathrm{MSH}$ was reduced by $70 \%$ compared with the control value. After 3 weeks, the $\alpha \mathrm{MSH}$ amount had increased again, to reach control level after 6 weeks. This level did not change up to 12 weeks (Fig. 1C).

\section{PC2 contents}

The pars intermedia contents of the processing enzyme PC2 were measured by Western blot analysis (Fig. 2). The antibody used for PC2 detection is directed against recombinant PC2 and recognizes both the precursor and the mature form of PC2. In white-adapted animals, no proPC2 could be detected and at all stages of black-adaptation the amount of pro-PC2 was 10- to 30-fold lower than the amount of mature PC2 (e.g. Fig. 2). In determining the dynamics of PC2 contents during background adaptation we considered only the mature active form of $\mathrm{PC} 2$, which is available to process POMC (Fig. 1D). In animals adapted to a white background a high level of PC2 was present, which diminished to $52 \%$ of the control value after 1 week of black background adaptation and stabilized after 3 weeks at a level slightly lower than the control value (Fig. 1D).

\section{Discussion}

\section{Dynamics of POMC biosynthesis and aMSH release}

In this study, long-term background adaptation has been investigated in Xenopus laevis by determining the time course of POMC biosynthesis and processing in the pituitary pars intermedia. In animals that had been adapted to a white background, biosynthetic activity is hardly detectable and a very low amount of POMC precursor protein is present in the pars intermedia, whereas the POMC peptide product $\alpha \mathrm{MSH}$ is present in high amounts. In response to black background adaptation, the 

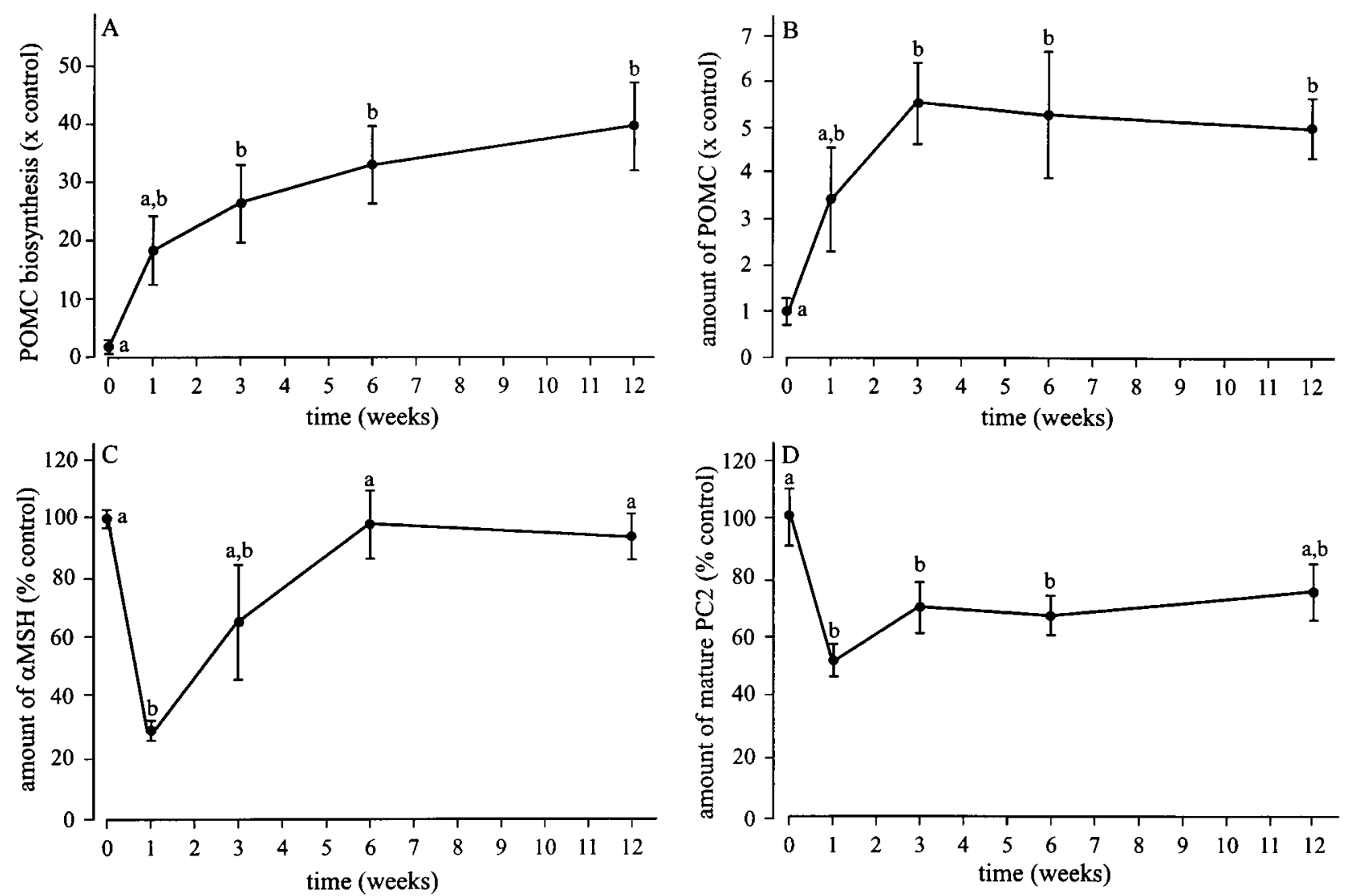

Figure 1 Animals were adapted to a white background for 3 weeks and either immediately killed ( $t=0$, controls), or subsequently adapted to a black background for 1, 3, 6 or 12 weeks. The average value of controls was set at 1 (A,B) or $100 \%$ (C,D). Data represent means \pm S.E.M. Data with a common superscript do not differ significantly $(P<0 \cdot 05)$. (A) Amount of newly synthesized POMC (expressed as fold increase relative to the control, $n=5$ ) determined by labeling with $\left[{ }^{3} \mathrm{H}\right]$ lysine. (B) Amount of POMC (expressed as fold increase relative to the control, $n=5$ ) determined by Western blot. (C) Amount of $\alpha \mathrm{MSH}$ (expressed as a percentage of the control value, $n=3$ ) determined by radioimmunoassay. (D) Amount of PC2 (expressed as percentage control, $n=5$ ) determined by Western blot.

rate of POMC biosynthesis and the POMC content become much higher than in white background-adapted animals, while initially the $\alpha \mathrm{MSH}$ content is strongly reduced. This indicates that the end product $\alpha \mathrm{MSH}$ and not the precursor POMC is the major storage product in animals on a white background. The initial reduction of aMSH in animals adapting to a black background prob-

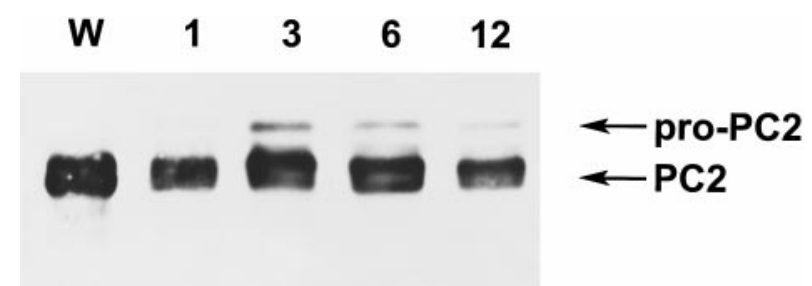

Figure 2 Example of Western blot analysis of PC2 in individual neurointermediate lobes of animals adapting to black background. $\mathrm{W}$ is the white background control; $1,3,6$, and 12 indicate the number of weeks adaptation to black background. Pro-PC2 is the precursor form of active PC2. ably reflects secretion from 'mature' secretory granules before the biosynthetic machinery can fully compensate for this release. The observed difference in POMC protein contents of the pars intermedia of white and black background-adapted animals is in line with previous studies that showed a much lower POMC mRNA level in white-adapted than in black-adapted animals (Martens et al. 1987). Prolonged adaptation of 12 weeks to a black background does not significantly change the situation seen at 3-6 weeks, indicating that steady-state levels are reached at about 3 weeks of adaptation.

The Xenopus background adaptation process offers a very good medium to study the in vivo dynamics of endocrine peptide biosynthesis in response to chronic physiological demands. One might suppose that long-term adaptation would lead to an increased effectiveness of melanotrope functioning, with the same degree of skin color adaptation resulting from a lower level of biosynthetic activity. However, the present study shows that the high steady-state level of biosynthetic activity 
reached after 3 weeks is maintained for up to 12 weeks. Apparently, three phases in Xenopus background adaptation can be distinguished. The initial phase is regulated by a $\beta$-adrenergic mechanism, acting at the level of the skin melanophore (van Zoest et al. 1989); within the first few hours of transfer of an animal from a white to a black background pigment dispersion in skin melanophores is induced by (nor)adrenaline. The second phase adaptive response is controlled by $\alpha \mathrm{MSH}$ release. It starts up slowly during the first days of adaptation, relying first on stores of $\alpha \mathrm{MSH}$, and ultimately leads to a balance between the biosynthesis, enzymatic processing and release of $\alpha \mathrm{MSH}$ after about 3 weeks of adaptation. In the third phase, lasting at least up to 12 weeks, steady-state levels of $\alpha \mathrm{MSH}$ biosynthesis, processing and release maintain the state of black-background adaptation.

\section{The role of $P C 2$ in POMC processing in vivo}

In animals adapted to a white background, a high level of mature PC2 was found, while after 1 week of black background adaptation the PC2 content was reduced. This reduction parallels the reduction in $\alpha \mathrm{MSH}$, suggesting co-storage of $\alpha \mathrm{MSH}$ and the mature form of PC2. The concomitant decreases of the $\alpha \mathrm{MSH}$ and PC2 contents during early adaptation suggest a coordinate release of the two molecules in response to transfer of the animal to a black background. This observation is in agreement with the demonstrated coexistence of $\alpha \mathrm{MSH}$ and PC2 in secretory granules in Xenopus melanotropes (Kurabuchi \& Tanaka 1997). Release of PC2 from neurointermediate pituitary lobes was previously reported in in vitro studies (Braks \& Martens 1994). The present study indicates that this release also occurs in the in vivo situation and, therefore, may have physiological relevance. This is the first time that PC2 protein dynamics in response to an environmental factor are demonstrated.

The co-expression of the POMC and PC2 genes has been well documented, i.e. high expression in fully black adapted animals and low expression in fully white adapted animals (Martens et al. 1987, Braks et al. 1992, Holthuis et al. 1995). In the present study, where the relative steady-state levels of active PC2 were determined during background adaptation, a partial 'depletion' of the enzyme was noted at 1 week adaptation, before its level stabilized with longer adaptations to black background. At 1 week adaptation the level of POMC biosynthesis and the steady-state level of POMC were also lower than the level they ultimately achieved with long adaptations. These observations indicate that the genes for both POMC and PC2 are only very slowly activated during black background adaptation. This indicates that the POMC and PC2 genes may be co-regulated. In the Xenopus pars intermedia, several inhibitory and stimulatory neuronal factors regulating POMC biosynthesis have been identified, including dopamine, neuropeptide $\mathrm{Y}$, thyrotropin- releasing hormone and sauvagine (Dotman et al. 1996, 1997). The Xenopus melanotrope cell may be an appropriate system to investigate whether PC2 gene expression is subject to the same complex regulations as the PC2 substrate POMC.

\section{Acknowledgements}

We are grateful to Dr S Tanaka and to Dr W J M van de Ven for kindly providing the anti-POMC antiserum and the anti-PC2 antiserum respectively. We thank RJC Engels for animal care and K P C Janssen and P M J M Cruijsen for technical assistance. This work was supported by a grant from the Foundation for Life Sciences, which is subsidized by the Netherlands Organization for Scientific Research (NWO), a grant from EU HCM (ERBCHRXCT920017) and a NWO/MW-INSERM exchange grant.

\section{References}

Ayoubi TAY, van Duijnhoven HLP, van de Ven WJM, Jenks BG, Roubos EW \& Martens GJM 1990 The neuroendocrine polypeptide 7B2 is a precursor protein. Journal of Biological Chemistry $26515644-15647$.

Bagnara JT \& Hadley ME 1973 Chromatophores and Color Change: The Comparative Physiology of Animal Pigmentation. Englewood Cliffs, New Jersey: Prentice Hall.

Benjannet S, Rondeau N, Day R, Chrétien M \& Seidah NG 1991 PC1 and PC2 are proprotein convertases capable of cleaving proopiomelanocortin at distinct pairs of basic residues. Proceedings of the National Academy of Sciences of the USA 88 3564-3568.

Berghs CAFM, Tanaka S, van Strien FJC, Kurabuchi S \& Roubos EW 1997 The secretory granule and proopiomelanocortin processing in Xenopus melanotrope cells during background adaptation. Journal of Histochemistry and Cytochemistry $\mathbf{4 5}$ 1673-1682.

Bliss CJ 1967 Statistics in Biology, vol 1. New York: McGraw-Hill.

Bonner WM \& Laskey RA 1974 A film detection method for tritium-labelled proteins and nucleic acids in polyacrylamide gels. European Journal of Biochemistry 46 83-88.

Braks JAM \& Martens GJM 1994 7B2 is a neuroendocrine chaperone that transiently interacts with prohormone convertase PC2 in the secretory pathway. Cell 78 263-273.

Braks JAM, Guldemond KCW, van Riel MCHM, Coenen AJM \& Martens GJM 1992 Structure and expression of Xenopus prohormone convertase PC2. FEBS Letters 305 45-50.

Day R, Schafer MK-H, Watson SJ, Chrétien M \& Seidah NG 1992 Distribution and regulation of the prohormone convertases PC1 and PC2 in the rat pituitary. Molecular Endocrinology 6 485-497.

Dotman CH, Cruijsen PMJM, Jenks BG \& Roubos EW 1996 Differential action of secreto-inhibitors on proopiomelanocortin biosynthesis in the intermediate pituitary of Xenopus laevis. Endocrinology 137 4551-4557.

Dotman CH, Maia A, Jenks BG \& Roubos EW 1997 Sauvagine and TRH differentially stimulate proopiomelanocortin biosynthesis in the Xenopus laevis intermediate pituitary. Neuroendocrinology 66 106-113.

Holthuis JCM, Jansen EJR, van Riel MCHM \& Martens GJM 1995 Molecular probing of the secretory pathway in peptide hormoneproducing cells. Journal of Cell Science 108 3295-3305. 
Jenks BG, van Overbeeke AP \& McStay BF 1977 Synthesis, storage, and release of MSH in the pars intermedia of the pituitary gland of Xenopus laevis during background adaptation. Canadian Journal of Zoology 55 922-927.

Jenks BG, Verburg-Van Kemenade BML \& Martens GJM 1988 Proopiomelanocortin in the amphibian pars intermedia: a neuroendocrine model system. In The Melanotropic Peptides, vol 1, pp 103-125. Ed ME Hadley. Boca Raton, Florida: CRC Press.

Jenks BG, Leenders HJ, Martens GJM \& Roubos EW 1993 Adaptation physiology: the functioning of pituitary melanotrope cells during background adaptation of the amphibian Xenopus laevis. Zoological Sciences 10 1-11.

Kurabuchi S \& Tanaka S 1997 Immunocytochemical localization of prohormone convertases PC1 and PC2 in the anuran pituitary gland: subcellular localization in corticotrope and melanotrope cells. Cell and Tissue Research 288 485-496.

Laemmli UK 1970 Cleavage of structural protein during the assembly of the head of bacteriophage T4. Nature 227 680-685.

Loh YP \& Gainer H 1977 Biosynthesis, processing and control of release of melanotropic peptides in the neurointermediate lobe of Xenopus laevis. Journal of General Physiology 70 37-58.

Marcinkiewicz M, Day R, Seidah NG \& Chrétien M 1993 Ontogeny of the prohormone convertases PC1 and PC2 in the mouse hypophysis and their colocalization with corticotropin and $\alpha$-melanotropin. Proceedings of the National Academy of Sciences of the USA 90 4922-4926.

Martens GJM, Jenks BG \& van Overbeeke AP 1982a Biosynthesis of pairs of peptides related to melanotropin, corticotropin and endorphin in the pars intermedia of the amphibian pituitary gland. European Journal of Biochemistry 122 1-10.

Martens GJM, Biermans PJ, Jenks BG \& van Overbeeke AP $1982 b$ Biosynthesis of two structurally different proopiomelanocortins in the pars intermedia of the amphibian pituitary gland. European Journal of Biochemistry 126 17-22.

Martens GJM, Soeterik F, Jenks BG \& van Overbeeke AP 1983 In vivo biosynthesis of melanotropins and related peptides in the pars intermedia of Xenopus laevis. General and Comparative Endocrinology 49 73-80.

Martens GJM, Civelli O \& Herbert E 1985 Nucleotide sequence of cloned cDNA for proopiomelanocortin in the amphibian Xenopus laevis. Journal of Biological Chemistry 260 13685-13689.

Martens GJM, Weterings KAP, van Zoest ID \& Jenks BG 1987 Physiologically induced changes in proopiomelanocortin mRNA levels in the pituitary gland of the amphibian Xenopus laevis. Biochemical and Biophysical Research Communications 143 678-684.

Maruthainar K, Peng-Loh Y \& Smyth DG 1992 The processing of $\beta$-endorphin and $\alpha$-melanotrophin in the pars intermedia of Xenopus laevis is influenced by background adaptation. Journal of Endocrinology 135 469-478. de Rijk EPCT, Jenks BG \& Wendelaar Bonga SE 1990 Morphology of the pars intermedia and the melanophore-stimulating cells in Xenopus laevis in relation to background adaptation. General and Comparative Endocrinology 79 74-82.

Roubos EW 1997 Background adaptation by Xenopus laevis: a model for studying neuronal information processing in the pituitary pars intermedia. Comparative Biochemistry and Physiology 118A 533-550.

Shapiro HH \& Wilk MB 1965 An analysis of variance test for normality. Biometrics 52 591-611.

Smith AI \& Funder JW 1988 Proopiomelanocortin processing in the pituitary, central nervous system, and peripheral tissues. Endocrine Reviews 9 159-179.

Steel RGD \& Torrie JH 1960 Principles and Procedures of Statistics. New York: McGraw-Hill.

van Strien FJC, Devreese B, van Beeumen J, Roubos EW \& Jenks BG 1995 Biosynthesis and processing of the N-terminal part of proopiomelanocortin in Xenopus laevis: characterization of $\gamma-\mathrm{MSH}$ peptides. Journal of Neuroendocrinology 7 807-815.

van Strien FJC, Jespersen S, van der Greef J, Jenks BG \& Roubos EW 1996 Identification of POMC processing products in single melanotrope cells by matrix-assisted laser desorption/ ionization mass spectrometry. FEBS Letters 379 165-170.

Thomas L, Leduc R, Thorne BA, Smeekens SP \& Steiner DF 1991 Kex2-like endoproteases PC2 and PC3 accurately cleave a model prohormone in mammalian cells: evidence for a common core of neuroendocrine processing enzymes. Proceedings of the National Academy of Sciences of the USA 88 5297-5301.

Thornton VF 1971 The effect of change of background color on the melanocyte-stimulating hormone content of the pituitary of Xenopus laevis. General and Comparative Endocrinology 17 554-560.

Weatherhead B \& Whur P 1972 Quantification of ultrastructural changes in the 'melanocyte-stimulating hormone cell' of the pars intermedia of the pituitary of Xenopus laevis, produced by change of background colour. Journal of Endocrinology 53 303-310.

Whur P \& Weatherhead B 1971 Rates of incorporation of $\left[{ }^{3} \mathrm{H}\right]$ leucine into protein of the pars intermedia of the pituitary in the amphibian Xenopus laevis after change of background colour. Journal of Endocrinology 51 521-532.

Wilson JF \& Morgan MA $1979 \alpha$-Melanotropin-like substances in the pituitary and plasma of Xenopus laevis in relation to colour change responses. General and Comparative Endocrinology 38 172-182.

van Zoest ID, Heijmen PS, Cruijsen PMJM \& Jenks BG 1989 Dynamics of background adaptation in Xenopus laevis: role of catecholamines and melanophore-stimulating hormone. General and Comparative Endocrinology 76 19-28.

Received 27 February 1998

Accepted 26 June 1998 